\title{
EVAPOTRANSPIRAÇÃO E COEFICIENTE DA CULTURA DO MAMOEIRO ${ }^{1}$
}

\author{
ROBSON P. POSSE ${ }^{2}$, SALASSIER BERNARDO ${ }^{3}$, ELIAS F. DE SOUSA ${ }^{4}$, \\ ROMILDO D. GOTTARDO 5
}

RESUMO: O trabalho teve como objetivos determinar a evapotranspiração da cultura (ETc) e o coeficiente da cultura $(\mathrm{Kc})$ para o mamoeiro (Carica papaya $\mathrm{L}$.). O experimento foi realizado na área de convênio UENF/PESAGRO-RIO, no município de Campos dos Goytacazes - RJ, no período de 25-4-2006 a 20-8-2007, utilizando o mamoeiro cultivar Híbrido UENF/CALIMAN01. Para a determinação da ETc e do Kc, foi utilizado lisímetro de pesagem com área superficial de $6 \mathrm{~m}^{2}$. A evapotranspiração de referência (ETo) foi estimada pelo método de Penman-Monteith (FAO). A evapotranspiração máxima da cultura foi de $2,9 \mathrm{~mm} \mathrm{dia}^{-1}$, aos 229 dias após o transplantio (DAT), sendo a evapotranspiração média da cultura, em todo o período, de $1,8 \mathrm{~mm} \mathrm{dia}^{-1}$. O valor do Kc do mamoeiro variou linearmente de 0,63 até 1,05 , do transplantio até 206 DAT. Após esse período, a variação do Kc relacionou-se inversamente com o diâmetro de copa, reduzindo-se ao valor médio mínimo de 0,81 , aos 300 DAT. Considerando todo o período em estudo, obteve-se Kc médio de 0,87 .

PALAVRAS-CHAVE: Carica papaya L., consumo hídrico, irrigação, manejo.

\section{EVAPOTRANSPIRATION AND CROP COEFFICIENT OF PAPAYA}

\begin{abstract}
This study aimed to determine the crop evapotranspiration (ETc) and the crop coefficient $(\mathrm{Kc})$ for of UENF/CALIMAN01 papaya hybrid (Carica papaya $\mathrm{L}$.). The experiment was conducted in an area of UENF/PESAGRO-RIO, in Campos dos Goytacazes, RJ, Brazil, from 4-25-2006 to 8-20-2007. To determine the ETc and Kc, a weighing lysimeter $\left(6 \mathrm{~m}^{2}\right)$ was used. The reference evapotranspiration (ETo) was determined by the Penmam-Monteith (FAO) method. The maximum crop evapotranspiration was of $2.9 \mathrm{~mm} \mathrm{day}^{-1}, 229$ days after the transplant (DAT), and the medium crop evapotranspiration during the experiment was of $1.8 \mathrm{~mm} \mathrm{day}^{-1}$. The value of crop coefficient $(\mathrm{Kc})$ varied linearly from 0.63 to 1.05 , the transplant to $206 \mathrm{DAT}$. After this period, the variation of Kc presented inversely relation with the canopy diameter, being reduced to a value medium minimum of 0.81 , to 300 DAT. Considering the whole period of study, it was obtained an average Kc of 0.87 .
\end{abstract}

KEYWORDS: Carica papaya L., water requirement, irrigation, management.

\section{INTRODUÇÃO}

Difundido em regiões de clima tropical e subtropical, o mamoeiro (Carica papaya L.) foi cultivado em 54 países em 2005 e, entre os três maiores produtores mundiais, o Brasil destacou-se como o maior produtor, chegando a 1.650 .000 toneladas, seguido por México e Nigéria, com 955.694 e 755.000 toneladas, respectivamente (FAO, 2007).

Com área cultivada de 36.500 ha em 2005, no Brasil (FAO, 2007), a Bahia apresenta-se como o maior produtor de mamão do País, seguido pelo Espírito Santo. A área colhida no ano de 2004, na Bahia, foi de 14.420 ha, enquanto no Espírito Santo foi de 9.868 ha. No Rio de Janeiro, a produção ainda é pequena; em 2004, a área colhida foi de 128 ha (IBGE, 2007). Porém, pode constituir-se em

\footnotetext{
${ }^{1}$ Extraído da Tese de Doutorado em Produção Vegetal do primeiro autor.

${ }^{2}$ Eng $^{\circ}$ Agrônomo, Doutor, Laboratório de Engenharia Agrícola, Universidade Estadual do Norte Fluminense, LEAG/UENF, Av. Alberto Lamego, 2000, Campos dos Goytacazes - RJ, Fone/Fax: (0XX22) 2726.1543, posse@uenf.br

${ }^{3}$ Eng $^{\mathrm{o}}$ Agrônomo, Prof. Titular, Departamento de Engenharia Agrícola, UENF, Campos dos Goytacazes - RJ, salassie@uenf.br

${ }^{4}$ Eng ${ }^{\circ}$ Agrícola, Prof. Associado, Departamento de Engenharia Agrícola, UENF, Campos dos Goytacazes - RJ, efs @uenf.br

${ }^{5}$ Técnico Agrícola, Laboratório de Engenharia Agrícola, UENF, Campos dos Goytacazes - RJ.

Recebido pelo Conselho Editorial em: 13-9-2007
}

Aprovado pelo Conselho Editorial em: 17-2-2009

Eng. Agríc., Jaboticabal, v.28, n.4, p.681-690, out./dez. 2008 
uma região competitiva em expansão e produção da cultura, considerando-se que as condições edafoclimáticas são similares à do Norte do Espírito Santo. Indícios de viabilidade da cultura do mamão para a região norte do Estado do Rio de Janeiro já foram observados. Algumas combinações híbridas ultrapassaram a estimativa de $150 \mathrm{t} \mathrm{ha}^{-1}$ (PEREIRA et al., 2002).

Para não comprometer o desenvolvimento da planta, toda a água consumida pela evapotranspiração deve ser reposta sob a forma de precipitação ou irrigação, de forma a manter no solo, umidade ideal para que as raízes consigam retirar a quantidade de água necessária, sem restrições. Assim, estudos da evapotranspiração e a estimativa dos coeficientes de cultura, nas diferentes fases de desenvolvimento, são de fundamental importância para o projeto e o manejo de irrigação, contribuindo para o aumento de produtividade e a otimização dos recursos hídricos e energéticos, que estão cada vez mais escassos.

Utilizado para expressar a relação entre a evapotranspiração da cultura (ETc) e a evapotranspiração de referência (ETo), o valor do coeficiente da cultura $(\mathrm{Kc})$ varia de acordo com as características da cultura, datas de plantio ou semeadura, estádio de desenvolvimento e, em menor escala, com a variação dos elementos climáticos (PEREIRA \& ALLEN, 1997; ALLEN et al., 1998; SEDIYAMA et al., 1998; BERNARDO et al., 2005).

A distribuição temporal dos valores do Kc, durante o ciclo de crescimento da cultura, constitui a curva de cultura (ALLEN et al., 1998). Tendo a ETo como caracterizadora da demanda evapotranspirativa, determinada pelas condições meteorológicas, e o Kc como expressão da demanda hídrica da planta, uma curva de cultura deve ser traçada para cada estádio de desenvolvimento da cultura (SEDIYAMA et al., 1998). Como não se pode utilizar um único valor de Kc para todas as situações climáticas, ALLEN et al. (1998) propõem ajustamentos em função das condições climáticas locais.

Diversos trabalhos vêm sendo conduzidos com o intuito de determinar a evapotranspiração de uma cultura ou a de referência, fazendo-se o uso de diferentes métodos, como o de balanço hídrico (MONTENEGRO et al., 2004; FREITAS \& BEZERRA, 2004), lisímetro de drenagem (CHAVES et al., 2005), microlisímetro com lençol freático constante (FRONZA \& FOLEGATTI, 2003) e lisímetros de pesagem (MIRANDA et al., 1999; SILVA et al., 2003; PAES, 2003; CARVALHO et al., 2006). O uso do lisímetro de pesagem serve como ferramenta-padrão em estudos de perda de água, pois mede direta e precisamente a evapotranspiração da cultura ou a de referência, integrando fatores ambientais que regem tal processo (ABOUKHALED et al., 1982; BERNARDO et al., 2005).

Apesar da expansão da cultura e da demanda por tecnologia, são poucas as informações que se tem a respeito da necessidade hídrica do mamoeiro, que possam auxiliar o manejo das irrigações, principalmente para o Estado do Rio de Janeiro. Em função disso, este trabalho teve como objetivo determinar o coeficiente da cultura $(\mathrm{Kc})$ do mamoeiro, utilizando a evapotranspiração da cultura obtida pelo lisímetro de pesagem e a evapotranspiração de referência estimada pelo método de Penman-Monteith FAO.

\section{MATERIAL E MÉTODOS}

O experimento foi conduzido na Estação Evapotranspirométrica do CCTA/UENF, localizada a $21^{\circ} 45^{\prime}$ de latitude sul, $41^{\circ} 18^{\prime}$ de longitude oeste e $11 \mathrm{~m}$ de altitude, na área de convênio UENF/E.E.C. PESAGRO-RIO, no município de Campos dos Goytacazes, região norte do Estado do Rio de Janeiro, no período de 25-4-2006 a 20-8-2007, utilizando o mamoeiro (Carica papaya L.) da variedade Híbrido UENF/CALIMAN01, plantado em fileiras simples, com espaçamento de 1,8 $\mathrm{m}$ x 3,6 m (representando por planta, área de 6,48 $\mathrm{m}^{2}$ ).

O clima da região é classificado, segundo classificação de Köeppen, como Aw, ou seja, tropical úmido, com inverno seco e chuvas máximas no verão. O solo da área experimental é um Cambissolo de origem fluvial, pouco profundo, com drenagem moderada a imperfeita. Apresenta 
como características os teores de areia, silte e argila de $78 \%, 3 \%$ e $19 \%$, respectivamente, umidade na capacidade de campo igual a $22,3 \%$ (em volume), umidade no ponto de murcha permanente igual a $11,6 \%$ (em volume) e densidade do solo igual a $1,81 \mathrm{~g} \mathrm{~cm}^{-3}$. Esses valores foram obtidos para a camada de 0 a $0,3 \mathrm{~m}$ de profundidade.

$\mathrm{O}$ fator de disponibilidade (f) para a cultura do mamoeiro foi considerado como 0,5 , e a profundidade de exploração de $80 \%$ das raízes do mamoeiro foi considerada como $0,3 \mathrm{~m}$, conforme recomendado por BERNARDO et al. (1996). Assim sendo, o limite de água disponível no solo para a cultura do mamão foi de $32 \mathrm{~mm}$.

As mudas foram preparadas em tubetes de $115 \mathrm{~cm}^{3}$, utilizando substrato em mistura com adubo (formulação NPK 14-14-14), na quantidade de 500 g para cada $25 \mathrm{~kg}$ de substrato. O preparo do solo na área de cultivo ocorreu 60 dias antes do transplantio das mudas e foi constituído de aração, gradagem e posterior aplicação e incorporação de calcário dolomítico, na quantidade de $1,2 \mathrm{t} \mathrm{ha}^{-1}$, quantidade necessária de acordo com análise do solo para a elevação da saturação de base a $80 \%$. As mudas foram transplantadas para a área experimental no dia 25-4-2006, quando essas atingiram altura de aproximadamente $20 \mathrm{~cm}$. Foram transplantadas três mudas por cova (em distribuição triangular de 30 × 30 × $30 \mathrm{~cm}$ ). A floração teve início no dia 18-7-2006, aos 84 dias após o transplantio (DAT), momento em que foi realizada a sexagem, deixando apenas uma planta por cova, de preferência as hermafroditas.

Foram aplicados $15 \mathrm{~L}$ de esterco de curral curtido (10 L na formação da cova e $5 \mathrm{~L}$ na linha entre plantas no momento da sexagem), $600 \mathrm{~g}$ de superfosfato simples e $60 \mathrm{~g}$ de cloreto de potássio. Aos 30 DAT, foram aplicados $30 \mathrm{~g} \mathrm{cova}^{-1}$ de sulfato de amônio e, aos 90 DAT, foram aplicados mais $100 \mathrm{~g} \mathrm{cova}^{-1}$ de sulfato de amônio, $100 \mathrm{~g} \mathrm{cova}^{-1}$ de superfosfato simples e $50 \mathrm{~g}^{\text {cova }}{ }^{-1}$ de cloreto de potássio.

O nitrogênio e o potássio foram aplicados mensalmente, utilizando o sulfato de amônia (com $20 \%$ de $\mathrm{N}$ ) e o cloreto de potássio (com $60 \%$ de $\mathrm{K}_{2} \mathrm{O}$ ) como fontes. No quarto, quinto e sexto meses após o transplantio, foram aplicados $20 \mathrm{~g}_{\text {planta }}{ }^{-1}$ de $\mathrm{N}$ e $36 \mathrm{~g}_{\text {planta }}{ }^{-1}$ de $\mathrm{K}_{2} \mathrm{O}$, e do sétimo mês em diante foram aplicados $30 \mathrm{~g} \mathrm{planta}^{-1}$ de $\mathrm{N}$ e $48 \mathrm{~g} \mathrm{planta}^{-1}$ de $\mathrm{K}_{2} \mathrm{O}$. Os micronutrientes foram aplicados no sexto mês, na quantidade de $20 \mathrm{~g}_{\text {planta }}{ }^{-1}$, utilizando como fonte o fertilizante MIB3 $(1,8 \% \mathrm{~B} ; 0,8 \% \mathrm{Cu} ; 3,0 \%$ Fé; $2,0 \% \mathrm{Mn} ; 0,1 \%$ Mo e $9,0 \% \mathrm{Zn})$.

Durante a condução do experimento, foram realizados controles de ervas daninhas, de pragas e doenças, seguindo os tratos culturais apropriados para a cultura do mamão, conforme recomendado por MARIN et al. (1995).

O sistema de irrigação utilizado foi o de microaspersão, utilizando-se de uma linha de emissores por linha de plantio, instalados no centro das linhas de plantio, numa disposição de 3,6 m entre linhas e de 3,6 m entre emissores, o que correspondeu a um emissor para duas plantas. Os microaspersores eram autorreguláveis, com vazão nominal de $70 \mathrm{~L} \mathrm{~h}^{-1}$, apresentando diâmetro molhado de $6 \mathrm{~m}$.

As irrigações foram programadas para sempre ocorrerem no intervalo de $00 \mathrm{~h} 00$ às $3 \mathrm{~h} 00$, período considerado sem evapotranspiração, por um sistema automatizado da marca Galcon, modelo Yarden Super 8. A drenagem do lisímetro, também automatizada, foi programada para ocorrer no mesmo período da irrigação, por intermédio de solenoides e válvulas de controle hidráulico, eliminando, dessa forma, qualquer volume de água aplicada ou precipitada em excesso.

$\mathrm{Na}$ determinação da evapotranspiração da cultura (ETc) do mamoeiro, foi utilizado lisímetro de pesagem nas dimensões de $3 \mathrm{~m}$ x $2 \mathrm{~m}\left(6 \mathrm{~m}^{2}\right)$ com $1 \mathrm{~m}$ de profundidade, em chapa galvanizada de aço e com bordadura de $5 \mathrm{~cm}$ acima do nível do solo. A base da balança é acessada por um túnel de alvenaria. O mamoeiro foi plantado em torno do lisímetro de pesagem, totalizando área plantada de $900 \mathrm{~m}^{2}(30 \mathrm{~m} \times 30 \mathrm{~m})$. Duas plantas ficaram dentro do lísimetro (Figura 1), obedecendo ao espaçamento entre plantas $(1,8 \mathrm{~m})$, cujo plantio ocorreu no sentido de maior comprimento do lisímetro $(3,0 \mathrm{~m})$. 


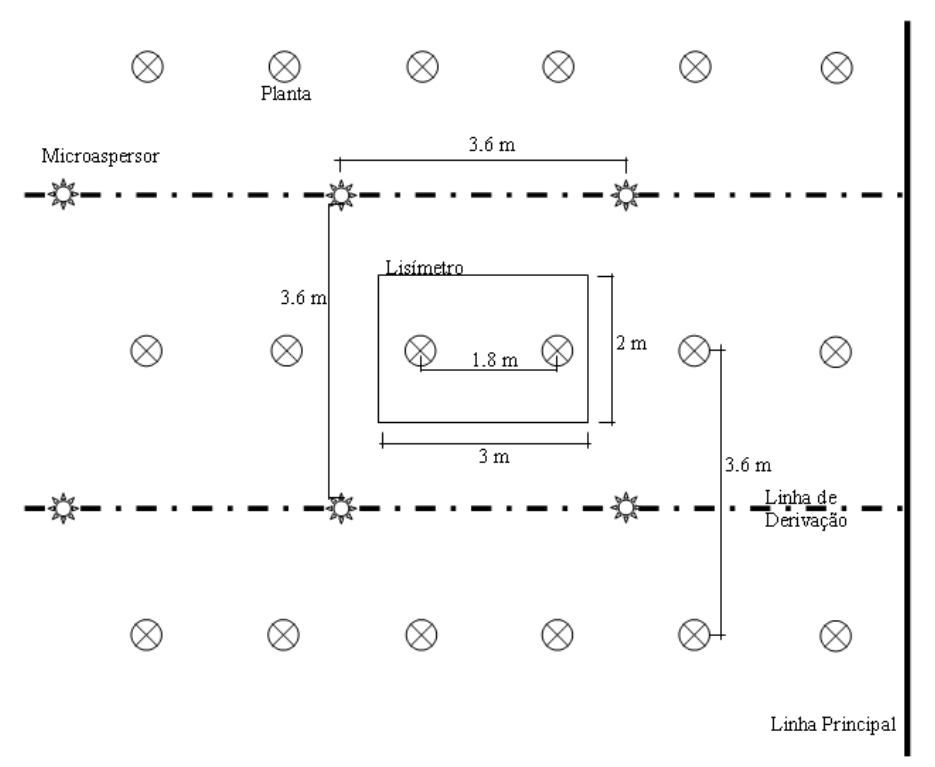

FIGURA 1. Croqui de localização do lisímetro de pesagem para a determinação do coeficiente da cultura do mamoeiro. Weighing lysimeter local for determining the crop coefficient of the papaya tree.

O lisímetro de pesagem possui uma balança eletrônica da marca J. Star, modelo 210, que permite a leitura de variação de peso de $0,58 \mathrm{~kg}(0,09 \mathrm{~mm})$. Os dados foram armazenados em intervalos de 20 minutos no Datalogger XPTO, modelo CD $10 \mathrm{Mega}$, os quais, posteriormente, foram transferidos para um computador, de programação específica, para posterior interpretação.

A variação diária do peso do lisímetro foi calculada pela diferença entre as leituras nos horários das 3h20min e das 23h40min. Assim, o manejo da irrigação foi realizado de forma que, no transplantio, o solo do lisímetro estando na capacidade de campo, as lâminas de água posteriormente aplicadas em cada irrigação superassem ligeiramente a evapotranspiração detectada pelo lisímetro, o que garantiu o suprimento adequado de água para a cultura. As irrigações foram realizadas três vezes por semana: às segundas, quartas e sextas-feiras.

Como no lisímetro foram cultivadas duas plantas de mamoeiro, o valor médio semanal de ETc foi calculado conforme eq.(1):

$$
\mathrm{ETc}=\frac{\mathrm{V}_{\mathrm{Lis}}}{\mathrm{nS}_{\text {plantio }}}
$$

em que,

$\mathrm{V}_{\mathrm{Lis}}$ - variação de volume médio semanal no lisímetro, L;

$\mathrm{n}$ - número de plantas instaladas no lisímetro, $\mathrm{n}=2$, e

$S_{\text {plantio }}$ - espaçamento de plantio da cultura, $S=3,6 \times 1,8=6,48 \mathrm{~m}^{2}$.

O coeficiente da cultura (Kc) para o mamoeiro foi calculado segundo a eq.(2):

$$
\mathrm{Kc}=\frac{\mathrm{ETc}}{\operatorname{EToK}_{\mathrm{s}} \mathrm{K}_{1}}
$$

Como a irrigação foi aplicada com frequência de três vezes por semana, assumiu-se o valor de Ks igual a 1,0 . [eq.(3)]:

O fator de localização $\left(\mathrm{K}_{1}\right)$ foi calculado conforme proposto por BERNARDO et al. (2005) 


$$
\mathrm{K}_{1}=\frac{\mathrm{P}}{100}
$$

em que,

$\mathrm{P}$ - percentagem da área sombreada (PAS) ou molhada (PAM), o que for maior, em \%.

No sistema de irrigação utilizado, conforme descrito anteriormente, devido às sobreposições dos jatos de água, toda a área cultivada era umedecida, o que poderia indicar a utilização do valor de $\mathrm{P}$ igual a $100 \%$. Porém, a área do lisímetro foi de $6 \mathrm{~m}^{2}$, ficando disponível efetivamente, para cada planta, a área de $3 \mathrm{~m}^{2}$. Como o lisímetro restringia o sistema radicular a essa área efetiva de $3 \mathrm{~m}^{2}$, as plantas não tinham acesso à água além desse limite de área. Dessa forma, a percentagem de área molhada $(\mathrm{PAM})$ efetivamente foi igual a PAM $=(3 / 6,48) 100=46 \%$. Enquanto a percentagem de área sombreada (PAS) foi menor que PAM, assumiu-se o valor P = PAM, e em outro caso, $\mathrm{P}=\mathrm{PAS}$.

A PAS foi calculada em função do diâmetro de copa (DC), conforme a eq.(4):

$$
\mathrm{PAS}=\frac{\pi \mathrm{DC}^{2}}{4 \mathrm{~S}_{\text {plantio }}}, \text { se DC menor que o espaçamento entre plantas }\left(\mathrm{L}_{\mathrm{P}}=1,8 \mathrm{~m}\right)
$$

em que,

$\mathrm{L}_{\mathrm{P}}$ - espaçamento entre plantas, $\mathrm{m}$.

Quando DC foi maior que $\mathrm{L}_{\mathrm{P}}$, fez-se a redução de PAS proporcional à intercepção das copas das plantas, conforme eq.(5):

$$
\mathrm{PAS}=\frac{\left(\frac{\pi \mathrm{DC}^{2}}{4}\right)-\frac{1}{2}\left(\frac{\theta D \mathrm{D}^{2}}{2}-\mathrm{L}_{\mathrm{p}} \mathrm{x}\right)}{\mathrm{S}_{\text {plantio }}}, \text { se } \mathrm{DC}>\mathrm{L}_{\mathrm{p}}
$$

em que,

$$
\begin{aligned}
& \theta=\arccos \left(\frac{L_{p}}{D C}\right), e \\
& x=2 \operatorname{sen}\left(\frac{\theta}{2}\right)
\end{aligned}
$$

A evapotranspiração de referência (ETo), média diária, foi estimada pelo método de PenmanMonteith FAO (ALLEN et al., 1998), com os dados meteorológicos necessários, sendo obtidos de estação climatológica instalada a poucos metros do local do experimento, da marca Thies Clima, modelo DL-15. Utilizaram-se valores médios, máximos e mínimos diários de temperatura e de umidade relativa do ar, valores médios de radiação solar global, coletados a 1,5 m de altura, e valores médios da velocidade do vento, coletados a $2 \mathrm{~m}$ de altura.

As plantas do lisímetro (duas hermafroditas) e as plantas ao redor (seis hermafroditas), escolhidas aleatoriamente, foram avaliadas mensalmente após a sexagem. Foram avaliadas as alturas das plantas, medindo-se da base da planta no solo até a inserção do último par de folhas, o diâmetro de caule a 0,2 m de altura e o diâmetro de copa (medido em duas posições - transversal e longitudinalmente em relação à linha de plantio).

De forma a quantificar a relação entre a temperatura e o crescimento da planta, em seus estádios de desenvolvimento, foi empregado o graus-dia $\left({ }^{\circ} \mathrm{C}\right.$ dia), contados a partir do transplantio das mudas para o campo, seguindo a equação $\left({ }^{\circ} \mathrm{C} . \operatorname{dia}=\mathrm{T}_{\text {med }}-\mathrm{T}_{\mathrm{b}}\right)$ apresentada por VILLA NOVA et al. (1972), em que: $\mathrm{T}_{\text {med }}$ - temperatura média diária $\left({ }^{\circ} \mathrm{C}\right)$, e $\mathrm{T}_{\mathrm{b}}$ - temperatura-base $\left({ }^{\circ} \mathrm{C}\right)$, sendo a temperatura-base para a cultura do mamão de $15^{\circ} \mathrm{C}$ (NAKASONE, 1988). 
Com o início da maturação (18-1-2007, aos 268 DAT), os frutos foram colhidos semanalmente, quando atingiam o estádio I de maturação, seguindo identificação apresentada por TATAGIBA \& OLIVEIRA (2000). Os frutos colhidos das plantas de dentro do lisímetro foram pesados e considerados no cálculo da determinação do coeficiente cultural. A última avaliação ocorreu no dia 20-8-2007, aos 482 DAT, o que representou o total de 16 meses de cultivo.

\section{RESULTADOS E DISCUSSÃO}

$\mathrm{Na}$ Tabela 1, são apresentados os valores totais e mensais das variáveis climáticas durante o cultivo do mamoeiro (de 25-4-2006 a 20-8-2007). A taxa média da ETo foi de 3,7 mm dia ${ }^{-1}$, totalizando $1.778 \mathrm{~mm}$ em todo o período. A precipitação total durante o período do experimento foi de $1.278 \mathrm{~mm}$, com precipitação média, em 12 meses, de $968 \mathrm{~mm}$, a qual foi bem próxima à média anual regional, que é de $1.023 \mathrm{~mm}$ (SOUSA, 1997), porém, insuficiente para suprir a ETo média em 12 meses, que foi de $1.346 \mathrm{~mm}$, bem como a ETc, justificando, assim, a necessidade de irrigação para um bom desenvolvimento da cultura.

TABELA 1. Evapotranspiração de referência mensal (ETo, $\mathrm{mm}$ mês $\mathrm{s}^{-1}$ ), precipitação total mensal (Prec, mm mês ${ }^{-1}$ ), temperaturas média (Tméd, $\left.{ }^{\circ} \mathrm{C}\right)$, máxima (Tmáx, ${ }^{\circ} \mathrm{C}$ ) e mínima (Tmín, ${ }^{\circ} \mathrm{C}$ ) mensais, umidade relativa média mensal (URméd, \%), radiação solar global média mensal (Rs, $\mathrm{MJ} \mathrm{m}^{-2} \mathrm{dia}^{-1}$ ) e velocidade do vento médio mensal a $2 \mathrm{~m}$ de altura $\left(\mathrm{u} 2, \mathrm{~m} \mathrm{~s}^{-1}\right)$, durante o período de condução da cultura do mamoeiro. Evapotranspiration of monthly reference $\left(\right.$ ETo, $\left.\mathrm{mm} \mathrm{month}^{-1}\right)$, monthly total precipitation (Prec, mm month ${ }^{-1}$ ), monthly average temperature (Tmed, ${ }^{\circ} \mathrm{C}$ ), monthly maximum temperature $\left(\mathrm{Tmax},{ }^{\circ} \mathrm{C}\right.$ ) and monthly minimum temperature (Tmín, ${ }^{\circ} \mathrm{C}$ ), monthly average relative humidity (URmed, \%), monthly average solar radiation ( $\mathrm{Rs}, \mathrm{MJ} \mathrm{m}^{-2}$ day $^{-1}$ ) and monthly average wind speed at 2 meters high $\left(\mathrm{u} 2, \mathrm{~m} \mathrm{~s}^{-1}\right)$, during the conduction of the papaya culture.

\begin{tabular}{lcrrrrrrrr}
\hline \multicolumn{1}{c}{ Mês } & Dias & ETo & Prec. & Tméd & Tmáx & Tmín & URméd & Rs & u2 \\
\hline abr./2006 & 5 & 19 & 7 & 23,0 & 28,2 & 19,2 & 79,5 & 14,1 & 1,4 \\
maio/2006 & 31 & 95 & 14 & 21,0 & 26,9 & 16,5 & 74,5 & 13,9 & 1,7 \\
jun./2006 & 30 & 84 & 28 & 20,0 & 25,8 & 15,6 & 76,8 & 13,1 & 1,8 \\
jul./2006 & 31 & 91 & 16 & 19,7 & 27,3 & 14,3 & 79,1 & 13,1 & 1,5 \\
ago./2006 & 31 & 116 & 38 & 21,1 & 27,3 & 16,8 & 78,3 & 15,2 & 2,3 \\
set./2006 & 30 & 119 & 42 & 20,9 & 26,2 & 17,0 & 76,6 & 15,7 & 2,7 \\
out./2006 & 31 & 129 & 122 & 22,4 & 27,1 & 19,4 & 82,3 & 18,0 & 2,6 \\
nov./2006 & 30 & 129 & 207 & 23,4 & 28,2 & 20,5 & 84,2 & 18,1 & 2,5 \\
dez./2006 & 31 & 145 & 84 & 24,7 & 29,9 & 21,2 & 83,1 & 19,6 & 2,2 \\
jan./2007 & 31 & 127 & 430 & 24,5 & 29,5 & 21,5 & 88,9 & 17,6 & 1,9 \\
fev./2007 & 28 & 146 & 50 & 25,5 & 30,8 & 21,6 & 79,9 & 24,4 & 1,5 \\
mar./2007 & 31 & 133 & 19 & 26,4 & 33,0 & 21,4 & 76,3 & 23,9 & 1,9 \\
abr./2007 & 30 & 90 & 66 & 24,8 & 30,2 & 20,5 & 83,2 & 9,6 & 1,6 \\
maio/2007 & 31 & 94 & 135 & 21,3 & 27,0 & 17,1 & 79,5 & 9,4 & 1,9 \\
jun./2007 & 30 & 91 & 10 & 20,7 & 27,5 & 16,0 & 81,4 & 8,9 & 1,8 \\
jul./2007 & 31 & 98 & 10 & 20,4 & 26,8 & 15,9 & 79,1 & 9,0 & 2,1 \\
ago./2007 & 20 & 72 & 0 & 20,5 & 27,1 & 15,7 & 79,8 & 13,0 & 1,9 \\
\hline Soma/ & 482 & 1.778 & 1.278 & & & & & & \\
Média & & & & 22,4 & 28,2 & 18,2 & 80,1 & 15,1 & 2,0 \\
\hline
\end{tabular}

Para melhor interpretação dos dados, minimizando maiores oscilações, ocorridas geralmente nos dias de irrigações ou precipitações, quando a taxa de evapotranspiração aumenta em virtude da maior disponibilidade hídrica evaporante no solo (PEREIRA et al., 1997), valores médios semanais (média de 7 dias) foram utilizados para estimar a ETc e a ETo, durante todo o período de 
desenvolvimento da cultura (Figura 2). A evapotranspiração máxima da cultura foi de 2,9 mm dia ${ }^{-1}$ (aos 229 DAT), e a evapotranspiração média da cultura em todo o período foi de $1,8 \mathrm{~mm} \mathrm{dia}^{-1}$, valor abaixo do encontrado por MONTENEGRO et al. (2004), na região norte do Ceará, que foi de $3,3 \mathrm{~mm} \mathrm{dia}^{-1}$, utilizando o mamoeiro da variedade "Sunrise Solo".

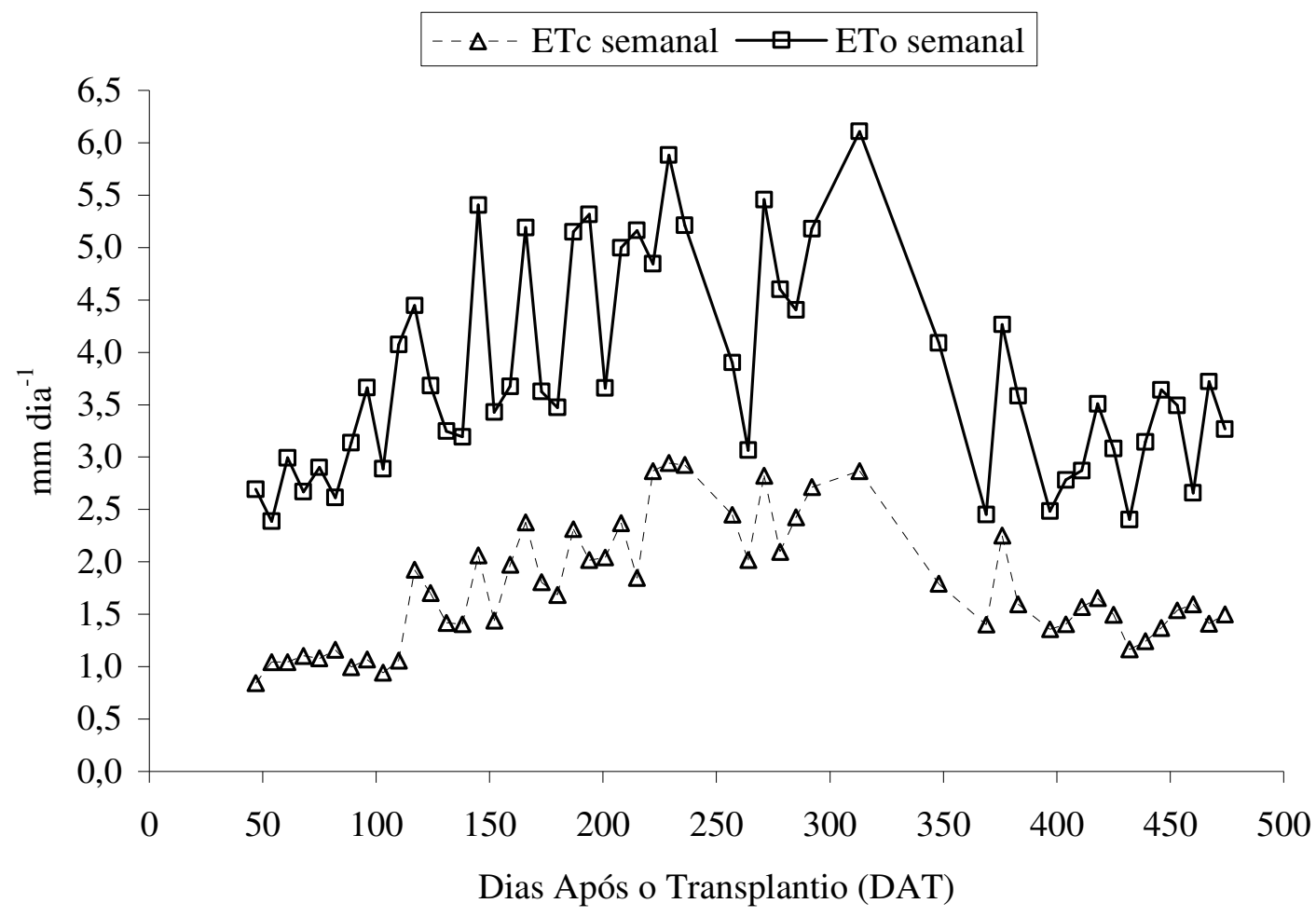

FIGURA 2. Valores médios semanais da evapotranspiração da cultura (ETc) e da evapotranspiração de referência (ETo) em função dos dias após o transplantio (DAT) do mamoeiro Híbrido UENF/CALIMAN01. Weekly average value of crop evapotranspiration (ETc) and the reference evapotranspiration (ETo) in function of days after transplanting (DAT) of UENF/CALIMAN01 hybrid papaya.

Na Figura 3, pode-se observar que as fases da cultura (inicial, crescimento, intermediário e final), conforme apresentado por ALLEN et al. (1998), não puderam ser observadas, nem o mesmo padrão, devido à variação do coeficiente de localização $(\mathrm{Kl})$ apresentado pelo mamoeiro. $\mathrm{O}$ valor de $\mathrm{Kl}$ inicialmente permaneceu constante e igual a 0,46 até que o diâmetro de copa (DC) atingisse o valor do espaçamento entre plantas $\left(\mathrm{L}_{\mathrm{p}}=1,8 \mathrm{~m}\right)$. A partir daí, a variação deu-se em função da oscilação do diâmetro de copa, que é comum na cultura, conforme pode ser observado nos trabalhos de SILVA (1999), MARINHO (2007) e LYRA (2007). O mamoeiro apresenta, durante seu ciclo de desenvolvimento, diâmetros de copa crescentes e decrescentes, o que é dependente das condições climáticas do local, da fase de produção ou até mesmo da variedade em cultivo.

Enquanto os valores de $\mathrm{Kl}$ permaneceram constantes e iguais a 0,46, o valor médio do $\mathrm{Kc}$ variou linearmente de 0,63 até o valor em torno de 1,05. Esse fato compreendeu dentro do período do transplantio até 206 DAT $\left(1.260{ }^{\circ} \mathrm{C}\right.$ dia), momento em que o diâmetro da copa se igualou ao espaçamento entre plantas. A partir do momento em que o DC excedeu o espaçamento entre plantas $(1,8 \mathrm{~m})$, o valor de $\mathrm{Kc}$ variou inversamente em relação aos valores de $\mathrm{Kl}$, atingindo o valor médio mínimo de 0,81 , enquanto $\mathrm{Kl}$ atingiu o seu valor máximo e igual a 0,65. Após o $\mathrm{Kl}$ atingir o valor máximo (360 DAT), esse tendeu a decrescer, enquanto o valor de $\mathrm{Kc}$ tendeu a se elevar. Posteriormente, espera-se que a variação dos valores de Kc dependerão inversamente da variação do diâmetro da copa observada por SILVA (1999), MARINHO (2007) e LYRA (2007). PEREIRA et al. (1997) e PEREIRA \& ALLEN (1997) afirmam que o Kc é dependente do índice de área foliar, bem como da fração de cobertura do solo pela vegetação. 


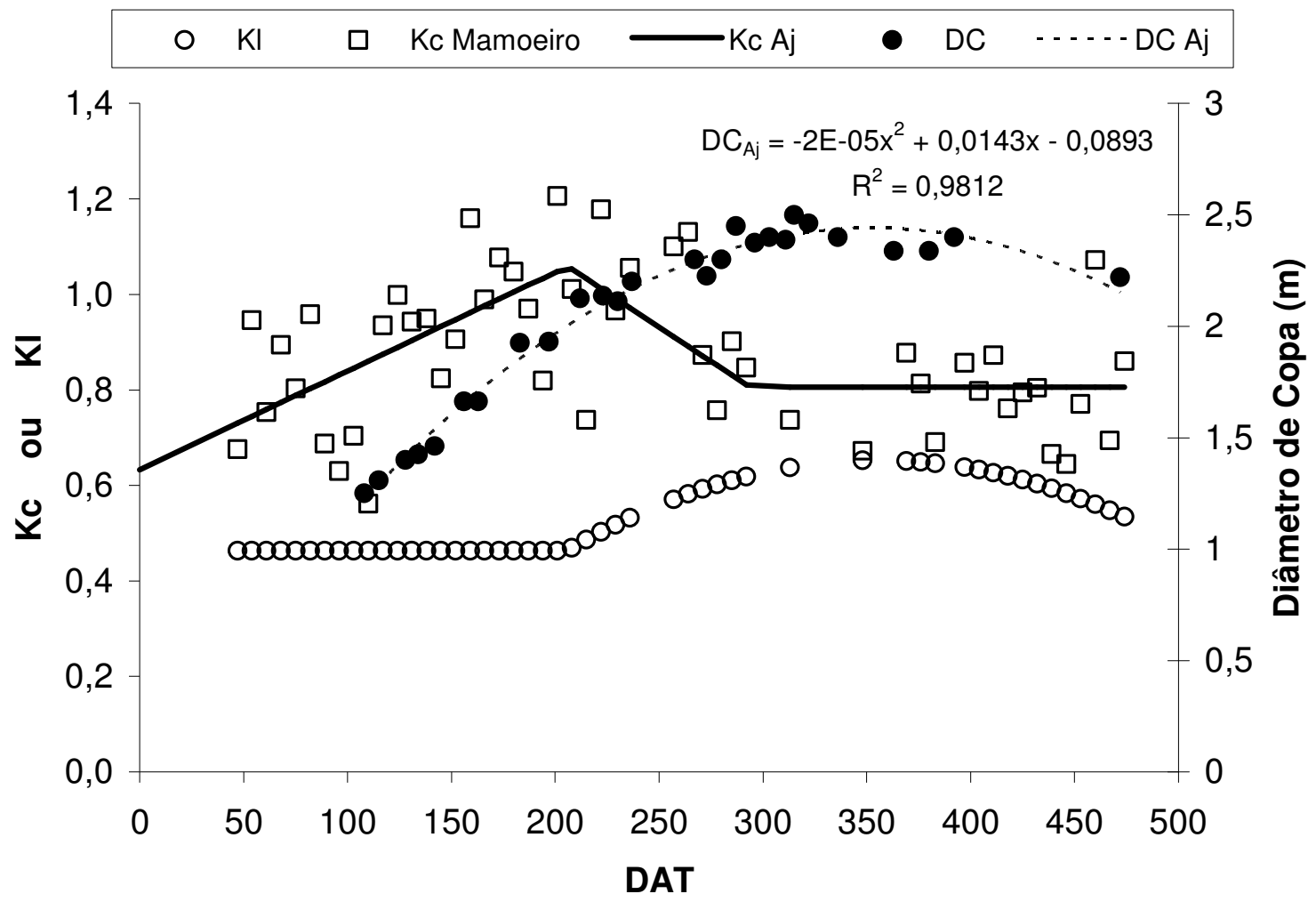

FIGURA 3. Variação do coeficiente de localização (Kl), do coeficiente de cultivo (Kc), do coeficiente de cultivo ajustado (Kc Aj) e do diâmetro de copa (DC), em função dos dias após o transplantio (DAT) do mamoeiro Híbrido UENF/CALIMAN01. Location coefficient variation $(\mathrm{KI})$, crop coefficient $(\mathrm{Kc})$, adjusted crop coefficient $(\mathrm{Kc} \mathbf{A j})$ and the diameter of crown (DC), in function of days after transplanting (DAT) of UENF/CALIMAN01 hybrid papaya.

Até os 482 DAT $\left(3.555^{\circ} \mathrm{C}\right.$ dia), considerando todo o período em estudo, obteve-se Kc médio de 0,87 para a cultura do mamoeiro Híbrido UENF/CALIMAN01, cultivado na região norte do Estado do Rio de Janeiro.

MONTENEGRO et al. (2004), ao determinarem o coeficiente da cultura do mamoeiro do grupo "Solo", pelo método de balanço hídrico, na região norte do Ceará, encontraram para os estádios, descritos por eles como vegetativo, floração/frutificação e floração/frutificação/ maturação, valores de Kc iguais a 0,54; 0,87 e 0,91, respectivamente, utilizando o método de Penman-Monteith FAO e, considerando todo o período, Kc médio de 0,85. MONTENEGRO et al. (2004) não discutiram como determinaram, ou se consideraram, os valores do coeficiente de localização $(\mathrm{Kl})$.

Os valores de $\mathrm{Kc}$ obtidos neste trabalho estão próximos dos valores dos coeficientes estimados por MONTENEGRO et al. (2004), apesar de o enfoque diferenciado em relação aos estádios da cultura e das variedades estudadas serem diferentes. Como as condições climáticas do local estão incorporadas na estimativa da ETo, o Kc varia essencialmente de acordo com as características da cultura, traduzindo em menor escala a variação dos fatores climáticos. Se as culturas tiverem características similares, os valores de Kc tendem a se tornar semelhantes de um local para outro (PEREIRA \& ALLEN, 1997; ALLEN et al., 1998).

MARINHO (2007) e LYRA (2007) utilizaram o Kc de 0,8 no período de 0 a 120 DAT, 1,0 entre 121 e 180 DAT e 1,2 após 180 DAT, para efeito de manejo da irrigação, em uma das maiores empresas produtoras de mamão na região norte do Estado do Espírito Santo. Exceto o valor utilizado após 180 DAT, os valores são similares ao obtido neste trabalho. 
As relações do coeficiente da cultura com o diâmetro de caule e com a altura da planta não foram significativas.

\section{CONCLUSÕES}

A evapotranspiração máxima da cultura foi de $2,9 \mathrm{~mm} \mathrm{dia}^{-1}$, aos 229 dias após o transplantio, e a evapotranspiração média da cultura, em todo o período, foi de $1,8 \mathrm{~mm} \mathrm{dia}^{-1}$.

$\mathrm{O}$ valor do coeficiente da cultura $(\mathrm{Kc})$ do mamoeiro variou linearmente de 0,63 até 1,05, do transplantio até 206 dias após o transplantio (DAT). Após esse período, a variação do Kc relacionou-se inversamente com o diâmetro de copa, reduzindo-se ao valor médio mínimo de 0,81, aos 300 DAT. Considerando todo o período em estudo, obteve-se Kc médio de 0,87.

\section{REFERÊNCIAS}

ABOUKHALED, A.; ALFARO, A.; SMITH, M. Lysimeters. Rome: FAO, 1982. 68 p. (Irrigation and Drainage Paper, 39)

ALLEN, R.G.; PEREIRA, L.S.; RAES, D.; SMITH, M. Crop evapotranspiration - guidelines for computing crop water requirements. Rome: FAO, 1998. 300 p. (Irrigation and Drainage Paper, 56)

BERNARDO, S.; SOARES, A.A.; MANTOVANI, E.C. Manual de irrigação. 7.ed. Viçosa: Editora UFV, 2005. $611 \mathrm{p}$.

BERNARDO, S.; CARVALHO, J.A.; SOUSA, E.F. Irrigação do mamoeiro. Campos dos Goytacazes: UENF, 1996. 20 p. (Boletim Técnico, 5)

CARVALHO, D.F.; SILVA, L.D.B.; FOLEGATTI, M.V.; COSTA, J.R.; CRUZ, F.A. Avaliação da evapotranspiração de referência na região de Seropédica - RJ, utilizando lisímetro de pesagem.

Revista Brasileira de Agrometeorologia, Santa Maria, v.14, n.2, p.187-95, 2006.

CHAVES, S.W.P.; AZEVEDO, B.M.; MEDEIROS, J.F.; BEZERRA, F.M.L.; MORAIS, N.B. Evapotranspiração e coeficiente de cultivo da pimenteira em lisímetro de drenagem. Revista Ciência Agronômica, Fortaleza, v.36, n.3, p.262-7, 2005.

FAO. FAOSTAT. FOOD AND AGRICULTURE ORGANIZATION OF THE UNITED

NATIONS. Estatistical Databases Agriculture. Disponível em: <http://faostat.fao.org/>. Acesso em: 25 maio 2007.

FREITAS, A.A.; BEZERRA, F.M.L. Coeficientes de cultivo da melancia nas suas fases fenológicas. Revista Ciência Agronômica, Fortaleza, v.35, n.2, p.319-25, 2004.

FRONZA, D.; FOLEGATTI, M.V. Water consumption of the estevia (Stevia rebaudiana (Bert.) Bertoni) crop estimated through microlysimeter. Scientia Agrícola, Piracicaba, v.60, n.3, p.595-9, 2003.

IBGE. INSTITUTO BRASILEIRO DE GEOGRAFIA E ESTATÍSTICA. Disponível em: $<$ http://www.sidra.ibge.gov.br/>. Acesso em: 25 maio 2007.

LYRA, G.B. Estimativa dos níveis ótimos econômicos de irrigação e de adubação nitrogenada nos mamoeiros (Carica papaya L.) cultivar golden e do híbrido UENF Calimam 01. 2007. 148 f. Tese (Doutorado em Produção Vegetal) - Universidade Estadual do Norte Fluminense Darcy Ribeiro, Campos dos Goytacazes, 2007.

MARIN, S.L.D.; GOMES, J.A.; SALGADO, J.S.; MARTINS, D.S.; FULLIN, E.A.

Recomendações para a cultura do mamoeiro dos grupos solo e formosa no Estado do Espírito Santo. 4.ed. Vitória: EMCAPA, 1995. 57 p. (Circular Técnica, 3)

MARINHO, A.B. Respostas dos mamoeiros cultivar golden e do híbrido UENF/CALIMANO1 sob diferentes lâminas de irrigação e doses de potássio. 2007. 125 f. Tese (Doutorado em Produção 
Vegetal) - Universidade Estadual do Norte Fluminense Darcy Ribeiro, Campos dos Goytacazes, 2007.

MIRANDA, F.R.; SOUZA, F.; RIBEIRO, R.S.F. Estimativa da evapotranspiração e do coeficiente de cultivo para a cultura do melão plantado na região litorânea do estado do Ceará. Engenharia Agrícola, Jaboticabal, v.18, n.4, p.63-70, 1999.

MONTENEGRO, A.A.T.; BEZERRA, F.M.L.; LIMA, R.N. Evapotranspiração e coeficientes de cultura do mamoeiro para a região litorânea do Ceará. Engenharia Agrícola, Jaboticabal, v.24, n.2, p.464-472, 2004.

NAKASONE, H. Y. Produção de mamão nos trópicos e subtrópicos. In: RIGGIERO, C. (Ed.). Mamão. Jaboticabal: FCAV-UNESP, 1988. p.19-42.

PAES, H.M.F. Demanda hídrica e função de produção da cultura do quiabeiro (Abelmoschus esculentus (L.) Moench) em Campos dos Goytacazes - RJ. 2003. 57 f. Tese (Mestrado em Produção Vegetal) - Universidade Estadual do Norte Fluminense Darcy Ribeiro, Campos dos Goytacazes, 2003.

PEREIRA, A.R.; NOVA, N.A.V.; SEDIYAMA, G.C. Evapo(transpi)ração. Piracicaba: FEALQ, 1997. $183 \mathrm{p}$.

PEREIRA, L.S.; ALLEN, R.G. Novas aproximações aos coeficientes culturais. Engenharia Agrícola, Jaboticabal, v.16, n.4, p.118-43, 1997.

PEREIRA, M.G.; MARIN, S.L.D.; MARTELLETO, L.A.P.; IDE, C.D.; MARTINS, S.P.;

PEREIRA, T.N.S. Melhoramento genético do mamoeiro (Carica papaya L.): comportamento de híbridos no Norte do Estado do Rio de Janeiro. In: CONGRESSO BRASILEIRO DE

FRUTICULTURA, 17., 2002, Belém. Anais... Belém: Sociedade Brasileira de Fruticulutura, 2002. 1 CD-ROM.

SEDIYAMA, G.C.; RIBEIRO, A.; LEAL, B.G. Relações clima-água-planta. In: FARIA, M.A.; SILVA, E.L.; VILELA, L.A.A.; SILVA, A.M. (Eds.) Manejo de irrigação. In: CONGRESSO BRASILEIRO DE ENGENHARIA AGRÍCOLA, 27., 1998, Lavras. Anais... Associação Brasileira de Engenharia Agrícola, 1998. p.46-85.

SILVA, J.G.F. Efeitos de diferentes lâminas e frequências de irrigação sobre o desenvolvimento e a produtividade do mamoeiro (Carica papaya L.). 1999. 90 f. Tese (Doutorado em Recursos Hídricos) - Universidade Federal de Viçosa, Viçosa, 1999.

SILVA, T.J.A.; MONTENEGRO, A.A.; RODRIGUES, J.J.V.; BONFIM, E.M.S. Aplicação de lisímetro de pesagem hidráulica na determinação da evapotranspiração de referência, em PetrolinaPE. Engenharia Agrícola, Jaboticabal, v.23, n.3, p.511-20, 2003.

SOUSA, E.F. Função de produção da cana-de-açúcar e da goiabeira em relação à irrigação. 1997. 119 f. Tese (Doutorado em Produção Vegetal) - Universidade Estadual do Norte Fluminense Darcy Ribeiro, Campos dos Goytacazes, 1997.

TATAGIBA, J.S.; OLIVEIRA, A.A.R. Tratamentos pós-colheita. In: RITZINGER, C.H.S.P.; SOUZA, J.S. Mamão: Fitossanidade. Cruz das Almas: Embrapa Mandioca e Fruticultura, 2000. cap.2, p.12-14.

VILLA NOVA, N.A.; PEDRO JR, M.J.; PEREIRA, A.R.; OMETTO, J.C. Estimativa de graus-dia acumulados acima de qualquer temperatura-base, em função das temperaturas máximas e mínimas. São Paulo: Universidade de São Paulo/Instituto de Geografia, 1972. 8 p. (Caderno de Ciências da Terra, 30) 